\title{
An update on the surgical management of pterygium and the role of loteprednol etabonate ointment
}

This article was published in the following Dove Press journal:

Clinical Ophthalmology

13 June 2014

Number of times this article has been viewed

\author{
John D Sheppard' \\ Arnulfo Mansur ${ }^{2}$ \\ Timothy L Comstock ${ }^{3}$ \\ John A Hovanesian ${ }^{4}$
}

'Virginia Eye Consultants, Norfolk, VA, USA; ${ }^{2}$ Airala's Laser and Cataract Institute, Miami, FL, USA; ${ }^{3}$ Bausch and Lomb, Inc., Rochester, NY, USA; ${ }^{4}$ Harvard Eye Associates, Laguna Hills, CA, USA
Correspondence: John D Sheppard Virginia Eye Consultants, 24I Corporate Blvd, Norfolk, VA 23502, USA

Tel +I 7576222200

Fax + I 7576224866

Email jsheppard@vec2020.com
Abstract: Pterygium, a sun-related eye disease, presents as wing-shaped ocular surface lesions that extend from the bulbar conjunctiva onto the cornea, most commonly on the nasal side. Pterygia show characteristic histological features that suggest that inflammation plays a prominent role in their initial pathogenesis and recurrence. Appropriate surgery is the key to successful treatment of pterygia, but there is also a rationale for the use of anti-inflammatory agents to reduce the rate of recurrence following surgery. Multiple surgical techniques have been developed over the last two millennia, but these initially had little success, due to high rates of recurrence. Current management strategies, associated with lower recurrence rates, include bare sclera excision and various types of grafts using tissue glues. Adjunctive therapies include mitomycin C and 5-fluorouracil, as well as the topical ocular steroid loteprednol etabonate, which has been shown to have a lower risk of elevated intraocular pressure than have the other topical ocular steroids. Here, the surgical management of pterygium is presented from a historical perspective, and current management techniques, including the appropriate use of various adjunctive therapies, are reviewed, along with an illustrative case presentation and a discussion of the conjunctival forceps designed to facilitate surgical management. Despite thousands of years of experience with this condition, there remains a need for a more thorough understanding of pterygium and interventions to reduce both its incidence and postsurgical recurrence. Until that time, the immediate goal is to optimize surgical practices to ensure the best possible outcomes. Loteprednol etabonate, especially the ointment formulation, appears to be a safe and effective component of the perioperative regimen for this complex ocular condition, although confirmatory prospective studies are needed.

Keywords: mitomycin C, recurrence, surgical management, 5-fluorouracil, pterygium, loteprednol etabonate

\section{Introduction}

The term "pterygium" is a Latinized version of the Greek term "pterygion" meaning "small wing"; 1,2 it is the name for the clinical condition consisting of wing-shaped ocular surface lesions extending from the bulbar conjunctiva onto the cornea, most commonly on the nasal side, that potentially result in blindness. On histological examination, the lesions show several characteristic features: inflammatory cells, neovascularization; remodeling of the extracellular matrix; and a leading edge (head) of altered limbal epithelial cells, followed by squamous metaplastic epithelium showing hyperplasia of the goblet cells, and an underlying stroma of activated, proliferating fibroblasts. These histological features allow pterygia to be classified into three types: proliferative, fibromatous, and atrophic sclerotic. ${ }^{3}$ Its clinical evaluation can be quantified by size, including invasion of the cornea and width at the base, as well as morphologic features. ${ }^{4}$ 
While there is no clear understanding of the pathogenesis of pterygium, it is probably multifactorial (including inherited factors and environmental triggers) in origin. Current evidence strongly suggests that ultraviolet (UV) light is probably the single most important factor., ${ }^{3,5-7}$ Several molecular mechanisms are activated by UV exposure, including oxidative stress and growth factor (GF) receptor signaling; these lead to the production of various factors, such as proinflammatory cytokines, GFs, and matrix metalloproteinases (MMPs), that appear to promote pterygium growth. ${ }^{3}$ In fact, both connective tissue growth factor and vascular endothelial growth factor (VEGF) are present in the epithelium of pterygia. ${ }^{8}$

Despite an extensive literature presence that goes back two millennia, pterygium remains somewhat of an enigma. Ancient writers who described its medical and surgical management included Hippocrates, Celsus, Pallus, Sushruta, and Aetius. They all recognized that treatment was difficult and that recurrences were almost inevitable. The first author to document a surgical approach appears to have been Celsus in $25 \mathrm{AD}^{2}$ However, little progress in preventing recurrences was described by later writers, even up to the early 20th century. In fact, some success in treating this condition and preventing recurrences has only recently been achieved. ${ }^{2}$

In recent years, there has been an increased awareness of the role of inflammation in both the pathogenesis of pterygium and in recovery following surgery. ${ }^{9,10}$ This has prompted the incorporation of topical corticosteroids, such as loteprednol etabonate (LE), into pterygium management protocols. The purpose of this article is to review the current strategies and the authors' personal experience managing this difficult condition, with added focus on the potential role of LE. We begin with a brief summary of LE.

\section{Loteprednol etabonate}

Compared with other corticosteroids, loteprednol etabonate (Lotemax; Bausch \& Lomb, Rochester, NY, USA) has a unique structure - the carbon 20 ketone group in the prednisolone core is replaced by an ester (Figure 1). ${ }^{11}$ LE is highly lipophilic, which facilitates its easy penetration through cell membranes, ${ }^{12}$ and it has been shown to have a therapeutic index more than 20-fold higher than that of other corticosteroids. ${ }^{13}$ LE was developed using "retrometabolic" engineering, to reduce its potential for adverse effects, ${ }^{14}$ it binds avidly to the glucocorticoid receptor, while the unbound drug is rapidly converted to inactive metabolites, minimizing the potential for unwanted effects, such as intraocular

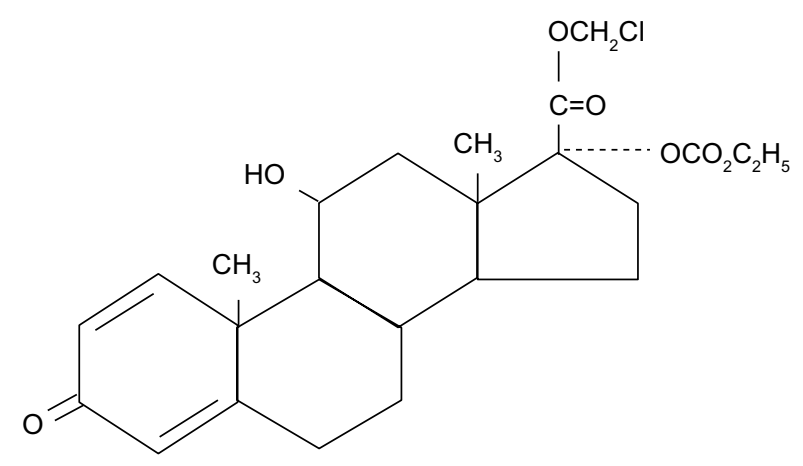

Figure I Structure of loteprednol etabonate.

pressure (IOP) elevation and cataractogenesis. ${ }^{11,13,15,16}$ Studies have confirmed a lower risk of IOP elevations with LE compared with other ocular steroid compounds. ${ }^{11,17-21}$

LE has three formulations that have been tested clinically for postoperative inflammation management in patients undergoing cataract surgery with intraocular lens implantation: a suspension,,${ }^{22,23}$ an ointment, ${ }^{24}$ and most recently, a gel ${ }^{25,26}$ (Table 1). Compared with the suspension formulation, the ointment and gel formulations of LE are expected to have some advantages, including better homogeneity and no need for resuspension by shaking, resulting in more consistent dosing. In addition, there is no preservative in the ointment formulation. Regardless of the formulation, LE significantly reduced postoperative anterior chamber inflammation (cells and flare) and pain compared with vehicle, in cataract surgery patients. ${ }^{11,22,24-26}$ Further, the proportion of patients requiring rescue medication was lower (approximately half) in the LE-treated group compared with the vehicle-treated group. Overall, there were no safety concerns noted with LE in these trials. Regardless of formulation, the mean IOP decreased $(1-2 \mathrm{mmHg})$ with LE treatment, and few LE-treated patients experienced an IOP increase $>10 \mathrm{mmHg}$.

There are currently no published controlled studies reporting clinical outcomes following the treatment of pterygium patients with LE, despite its apparent widespread use for this condition and well-documented efficacy in other postoperative indications. In a pilot study, the treatment of pterygium patients with LE twice daily (BID) for 14 days led to an approximate $50 \%$ increase in glucocorticoid receptor migration to the cell nucleus in the pterygium head tissue, as demonstrated using Western blot analysis of biopsied pterygium tissue, suggesting that perioperative treatment with topical LE could result in favorable clinical outcomes in pterygium removal..$^{27,28}$ 
Table I Clinical studies comparing LE with vehicle, in the treatment of postoperative pain and inflammation following cataract surgery*

\begin{tabular}{|c|c|c|c|c|c|}
\hline \multirow[t]{2}{*}{ Parameter } & \multicolumn{5}{|l|}{ Study } \\
\hline & Stewart et $\mathrm{al}^{22}$ & $\begin{array}{l}\text { LE postoperative } \\
\text { study group }^{23}\end{array}$ & Comstock et $\mathrm{al}^{24}$ & Fong et $\mathrm{al}^{25}$ & Rajpal et $\mathbf{a l}^{26}$ \\
\hline LE formulation & Suspension & Suspension & Ointment & Gel & Gel \\
\hline Total patients randomized & 227 & 203 & 805 & 407 & 406 \\
\hline \multirow{3}{*}{$\begin{array}{l}\text { Proportion of patients with } \\
\text { resolution of } \mathrm{ACl} \text { at the final } \\
\text { study visit }\end{array}$} & LE: $64 \%$ & LE: $55 \%$ & LE: $46 \%$ & LE: $54.9 \%$ & LE: $47.3 \%$ \\
\hline & Vehicle: $29 \%$ & Vehicle: $28 \%$ & Vehicle: $21 \%$ & Vehicle: $28.4 \%$ & Vehicle: $22.2 \%$ \\
\hline & $P<0.00$ I & $P<0.00$ I & $P<0.00$ I & $P<0.00$ I & $P<0.00$ I \\
\hline \multirow{2}{*}{$\begin{array}{l}\text { Patients with IOP elevations of } \\
\geq 10 \mathrm{mmHg} \text { over baseline, } \mathrm{n}(\%)\end{array}$} & LE: 3 (I.4\%) & LE: 0 (0.0\%) & LE: 3 (0.7\%) & LE: I (0.5\%) & LE: I (0.5\%) \\
\hline & Vehicle: $0(0.0 \%)$ & Vehicle: I (I.0\%) & Vehicle: I (0.2\%) & Vehicle: 0 (0.0\%) & Vehicle: I (0.5\%) \\
\hline
\end{tabular}

Note: *In all studies, patients received LE or vehicle four times daily for 14 days.

Abbreviations: $\mathrm{ACl}$, anterior chamber inflammation (sum of anterior chamber cells and flare); IOP, intraocular pressure; LE, loteprednol etabonate.

\section{Current concepts in pterygium management \\ Historical techniques}

The first reported surgical approach to pterygium management was described by Celsus, in which a needle and thread were passed under the pterygium. The thread was then elevated, the pterygium was completely lifted from the cornea to the canthus using a sawing motion, and the pterygium was excised. Unfortunately, this approach was often associated with pain, as well as blindness. Later, in the 16th century, it was noted that this operation should rarely be performed due to its dangers and the risk of recurrence. ${ }^{2}$ From the 1800 s to the 1930s, various techniques were developed, but none proved particularly successful. Though excision with simple conjunctival closure had good short-term results and few complications, the recurrence rates were high. ${ }^{2}$ In the first half of the 20th century, transplantation of the pterygium head away from the cornea, or redirection, was the most commonly used approach. However, though a relatively simple procedure with few complications, it failed to solve the major problem, that of recurrence, and was eventually replaced. ${ }^{2}$

\section{Current management techniques}

Bare sclera excision

The bare sclera technique heralded a major change in the surgical approach to pterygium, in the 1940s. This technique originally involved the complete excision of the pterygium head and removal of some of the adjacent normal nasal bulbar conjunctiva along with excision of the underlying Tenon's capsule tissue, which then resulted in a bare sclera. Following suture of the surrounding normal bulbar conjunctiva to the sclera, several millimeters of the sclera next to the limbus were left bare. The corneal epithelium then healed before it was possible for the conjunctival epithelium to reach the limbus. Thus the bare sclera technique compromised limbal stem cells. This technique has been subsequently refined, but when used alone, the recurrence rate is unacceptably high $(30 \%-80 \%) .{ }^{29}$ Therefore, some surgeons today use this approach in combination with various adjunctive therapies, to reduce the recurrence rate. , $29,30^{2}$

Another approach to pterygium surgery involves grafting. This strategy was first described in 1876, starting with mucous membrane grafting and then, conjunctival autografting as well as limbal conjunctival autografting. Conjunctival autografting is still widely used and considered the procedure of choice for primary and recurrent pterygium, due to its convenience and low recurrence rates $(2 \%-39 \%){ }^{2,29} \mathrm{~A}$ recent meta-analysis suggested that limbal conjunctival autografting has lower recurrence rates than do the bare sclera technique and conjunctival autografting, with no difference between it and amniotic membrane grafts. ${ }^{31}$ Large-scale, randomized, controlled studies are needed to better compare the recurrence rates among the various techniques.

\section{Amniotic membrane grafts}

The use of amniotic membrane grafts has been considerably refined subsequent to its original description in $1947 .{ }^{2}$ The amniotic membrane, the placenta's inner lining, is composed of three layers: a single epithelial layer; a thick basement membrane; and an avascular stroma. ${ }^{32}$ Several characteristics of amniotic membrane appear to make it suitable for treating pterygium, including its anti-inflammatory, anti-scarring, and anti-angiogenic properties. ${ }^{29}$ Once harvested, amniotic membrane can be used fresh or preserved (either freeze-dried or cryopreserved). Unfortunately, fresh amniotic membrane is usually not used in developed countries, due to the need to exclude infections, such as human immunodeficiency virus 
(HIV) and hepatitis. ${ }^{29}$ While some clinical trials of amniotic membrane grafts for the treatment of pterygium reported an unacceptably high recurrence rate compared with conjunctival autograft, it may provide a superior alternative for selected cases. ${ }^{29,30,33,34}$ Others have suggested that amniotic membrane may be combined with conjunctival autografting techniques, with the amnion used in the subconjunctival space as a natural inhibitor of fibrosis. Recurrence rates as low as $0.7 \%$ have been reported with this technique. ${ }^{35}$

\section{Role of tissue glue}

Fibrin glue can replace or augment sutures when attaching conjunctival grafts or amniotic membrane, significantly shortening operating times and decreasing postoperative discomfort, as well as decreasing recurrence rates. ${ }^{29}$ In general, fibrin glue consists of two main components: a sealer protein concentrate containing fibrinogen and a fibrinolysis inhibitor, and a thrombin and calcium chloride solution. When mixed at the time of application, the two solutions interact and mimic the clotting cascade, creating adhesion, while allowing the surgeon from 10-60 seconds to complete membrane alignment and orientation. The clot then dissolves after 1-2 weeks, providing adequate time for healing. ${ }^{36}$ Three products are currently available for use in the USA: Tisseel and Artiss, produced by Baxter International, Inc. (Deerfield, IL, USA); and Evicel ${ }^{\circledR}$, produced by Ethicon, Inc. (Somerville, NJ, USA). ${ }^{36}$ The storage requirements and specific usage instructions differ among the available formulations.

Since fibrin adhesives are prepared from pooled donor sources, there is a small but finite risk of infection, such as hepatitis and HIV, as well as of anaphylactic reaction. ${ }^{36}$ The infection risk is reduced by testing donors for viral markers, at the time of donation and 6 months later, as well as by sterilization of the products by gamma irradiation and treatment with detergents or solvents. ${ }^{36}$ Recombinant biotechnology could provide an ideal source of fibrinogen and thrombin, thus completely bypassing the viral contamination issues. Interestingly, a recent study suggested autologous fibrin in blood as a useful alternative to fibrin glue ${ }^{37}$ for pterygium surgery, though preparation can be laborious, requiring special equipment not available to most surgeons.

\section{Adjunctive therapies}

Various adjunctive therapies have been used with pterygium surgery, in an attempt to reduce the risk of postoperative recurrence. Two of these, mitomycin $\mathrm{C}$ and 5-fluorouracil (5-FU), are commonly employed by contemporary pterygium and glaucoma surgeons.

\section{Mitomycin C}

Mitomycin $\mathrm{C}$ is a potent alkylating agent that interferes with deoxyribonucleic acid (DNA) replication, particularly in cells that are growing actively. It also interferes with ribonucleic acid (RNA) and protein synthesis. The use of topical mitomycin $\mathrm{C}$ as an adjunct to pterygium surgery to inhibit the growth of fibroblasts was first described in 1963 and actively investigated in the late $1980 \mathrm{~s} .{ }^{38}$ Mitomycin $\mathrm{C}$ treatment combined with conjunctival grafting techniques significantly reduces the recurrence of both primary and recurrent pterygia compared with the bare sclera technique alone. ${ }^{29,39,40}$ After almost 3 years of follow up, patients treated for recurrent pterygium with intraoperative mitomycin $\mathrm{C}(0.02 \%)$ had a significantly lower rate of recurrence compared with those managed with the bare sclera technique alone $(12.5 \%$ vs $35.6 \%)(P=0.027){ }^{40}$

Two approaches have been developed for applying mitomycin $\mathrm{C}$ : postoperative use of topical eye drops and intraoperative use of mitomycin $\mathrm{C}$-soaked sponges. Both have similar recurrence rates. Adjunctive mitomycin $\mathrm{C}$ treatment is not without risk and has been associated with rare but severe long-term complications, including persistent epithelial defects of both the cornea and sclera, endophthalmitis, infectious scleritis, perforation, and scleral necrosis. ${ }^{29,41}$

A recent prospective, randomized study that included follow up on 78 eyes (78 patients) showed that conjunctival autografting and conjunctival-limbal autografting followed intraoperatively by a 3-minute application of $0.02 \%$ mitomycin $\mathrm{C}$ was associated with no significant difference in the pterygium recurrence rate, at 1-year follow up, between the two procedures. ${ }^{42}$ In another trial involving 41 eyes (37 patients) undergoing pterygium surgery, intraoperative mitomycin $\mathrm{C}(0.02 \%)$ was associated with a similar recurrence rate at 36 months mean follow up compared with conjunctival autograft alone $(14.3 \%$ vs $5.0 \%)(P=0.317)$ in patients with primary pterygium. ${ }^{43}$ Further studies of adjuvant mitomycin $\mathrm{C}$ treatment are necessary. ${ }^{30}$

\section{5-Fluorouracil}

5-FU, a fluorinated pyrimidine, also inhibits the proliferation of fibroblasts, but through different mechanisms involving the inhibition of thymidylate synthetase and other enzymes related to nucleic acid biosynthesis. ${ }^{38,44}$ Though the use of 5-FU as an adjunct to pterygium surgery has so far been associated with only minor and transient complications, there have been only few trials of its use in this way. On the other hand, serious complications have been reported when 5-FU has been used for glaucoma, especially ocular surface 
complications leading to severe epitheliopathy and corneal infections. ${ }^{38}$ The use of 5-FU as an adjuvant to conjunctival autograft post pterygium excision had a lower but not statistically different rate of recurrence compared with low-dose mitomycin-C $(0.01 \%)$, at 35 weeks mean follow up $(8.7 \%$ vs $11.8 \%)(P=0.7) .{ }^{45}$ Further long-term trials are needed to adequately evaluate the long-term safety and efficacy of 5-FU and other adjunctive treatments. ${ }^{29}$

\section{Surgical outcomes}

Pterygium surgery has four principal goals: restoration of an uninterrupted refractive ocular surface; a low recurrence rate; minimization of complications; and a satisfactory cosmetic outcome.

\section{Immediate complications}

Appropriate postoperative care helps reduce complications, but immediate complications can include excessive bleeding, conjunctival chemosis, graft edema, hematoma below the graft, a localized epithelial defect, loose sutures, conjunctival wound dehiscence, infection, and corneal scarring. While some complications may resolve without intervention, such as a localized epithelial defect or conjunctival chemosis, others require specific management. ${ }^{46}$

\section{Late complications}

The major late complication following pterygium surgery is recurrence. Recurrence rates vary by procedure, with bare sclera excision having the highest rate, followed by excision with amniotic membrane grafting, and by conjunctival autografting. ${ }^{46}$ One study reported a $0.7 \%$ rate of recurrence in primary pterygium, using a combination of conjunctival autograft and placement of amniotic membrane in the subconjunctival space. ${ }^{35}$ The risk factors for recurrence include male sex and a history of high sun exposure. ${ }^{47}$ Nontranslucent pterygia have been associated with an increased risk of recurrence, ${ }^{3}$ as have several biomarkers related to proliferation, inflammation, fibrosis, and angiogenesis. While further evaluation of these important biomarkers is needed, they point out the need to develop treatments that target specific receptors if the goal of eliminating recurrence is to be achieved. ${ }^{3}$

Other late complications include those related to adjunct therapy (such as mitomycin C), suture-related inflammation, Tenon's capsule cyst, diplopia and strabismus, scleral complications, corneal perforation, graft inversion or retraction, lens changes, and graft necrosis, as well as more unexpected complications, such as ptosis, entropion, symblepharon, and iris atrophy. ${ }^{46}$
Long-term results were recently reported for the Pterygium Extended Removal Followed by Extended Conjunctival Transplantation (PERFECT) study, which analyzed 1,000 consecutive pterygium procedures between August 2001 and September 2009, with a mean follow up of 616 days. ${ }^{48}$ Of these cases, $81 \%$ were primary pterygia and $19 \%$ were recurrent. There was only one postoperative recurrence $(0.1 \%)$ in this series. Overall, six patients required further surgery, due to hyperemic graft (three patients), exotropia (one patient), granuloma (one patient), inclusion cyst (one patient), and recurrence (one patient). ${ }^{48}$ The results of this study involving a single surgeon employing relatively large excisions and grafts suggest an extremely low recurrence rate, an acceptable complication rate, and good cosmetic outcomes. ${ }^{48}$ However, replication of these findings by surgeons in other centers is needed.

\section{Specific pterygium strategies}

With the above as background, the techniques and approaches of two of the authors (AM and JS) will be presented in detail, followed by a case presentation.

\section{Approach and techniques}

The surgical procedure selected depends primarily on the clinical presentation. A small but elevated pterygium with surface staining and chronic discomfort and foreign body sensation may require minimal corneal surgery with a rotational flap. On the other hand, a large recurrent pterygium with symblepharon, entropion, and medial rectus restriction may require staged surgery, collaboration with an oculoplastic surgeon, and extensive ocular surface reconstruction, with amniotic membrane or buccal mucosal grafting. Thus, the variety of procedures, enhancements, and modifications can be ranked in terms of complexity (Table 2).

Several technical points are keys to success. These issues should all be addressed and a plan formulated prior to surgical intervention.

\section{Preoperative preparation}

The surgery is best planned when the patient can avoid irritating environments for at least 3 weeks postoperatively or for 6 weeks for more irritated and inflamed cases or for recurrent cases. If at all possible, surgery should be performed after the fall equinox and prior to the spring equinox in the Northern Hemisphere, to avoid significant seasonal and outdoor activity-driven ultraviolet exposure.

Preoperatively, all ocular surface inflammation should be controlled, including allergy, blepharitis, conjunctivitis, 
Table 2 Surgical techniques for pterygium in order of complexity

\begin{tabular}{ll}
\hline $\begin{array}{l}\text { Rank by } \\
\text { complexity }\end{array}$ & Procedure \\
\hline I & $\begin{array}{l}\text { Local excision of pingueculum and pterygium with a } \\
\text { single small rotational conjunctival flap, closed with } \\
\text { buried I0-0 nylon suture }\end{array}$ \\
2 & $\begin{array}{l}\text { Addition of topical mitomycin C to the procedure } \\
\text { More extensive conjunctival excision with both an } \\
\text { inferior and a superior rotational conjunctival flap, }\end{array}$ \\
4 & $\begin{array}{l}\text { closed with I0-0 nylon suture } \\
\text { superotemporal free conjunctival autograft or an amniotic }\end{array}$ \\
5 & $\begin{array}{l}\text { membrane graft to completely cover all bare sclera } \\
\text { Consideration of autologous serum glue, using only } \\
\text { local hemorrhage to bind a small amniotic membrane or } \\
\text { conjunctival graft }\end{array}$ \\
6 & $\begin{array}{l}\text { Fibrin tissue glue (Evicel [Ethicon, Inc., Somerville, NJ, } \\
\text { USA] or Tisseel [Baxter International, Inc., Deerfield, IL, } \\
\text { USA]) to secure the rotational and grafted ocular surface, } \\
\text { often supplemented with buried I0-0 nylon suture } \\
\text { Additional deep dissection of rectus insertion cicatrix }\end{array}$ \\
7 & $\begin{array}{l}\text { Additional dissection, grafting, or sequential surgery to } \\
\text { correct symblepharon and forniceal cicatrization }\end{array}$ \\
\hline
\end{tabular}

and dry eye; LE is also useful for this purpose, using the suspension or gel formulation four times daily (QID) and the ointment every evening (QHS). Some patients can also use LE ointment during the day, which is strongly recommended for patients with preservative hypersensitivity. The ointment formulation avoids the need for shaking prior to administration and ensures optimal dosing homogeneity. Similarly, LE gel also avoids shaking requirements and minimizes preservative exposure. Some surgeons also use a topical antibiotic preoperatively, for example, besifloxacin BID or three times daily in the affected eye, starting 1 day before surgery, then postoperatively for 7 to 14 days when corneal epithelialization is complete. Unlike cataract surgery, topical nonsteroidal anti-inflammatory drugs (NSAIDs) are not given preoperatively for pterygium surgery. Oral NSAIDs and anticoagulants should be temporarily discontinued.

\section{Surgical procedure}

The choice of anesthetic depends on the type of surgery: an injection of retrobulbar or peribulbar anesthetic is appropriate if extensive surgery, lengthy operative time, muscle manipulation, or adjunctive lid procedures are anticipated; topical or light anterior subconjunctival anesthesia should be sufficient for relatively simpler cases in cooperative patients. Light anterior subconjunctival lidocaine with 1:100,000 epinephrine, injected with a 30-gauge needle directly beneath the lesion, should be considered to simplify anesthesia and provide excellent hemostasis.
In addition, topical dilating drops are useful in pterygium excision: the sympathomimetic promotes conjunctival vasoconstriction and hemostasis, while the parasympatholytic provides relief of ciliary spasm pain postoperatively. A central corneal pledget of Muroce ${ }^{\circledR}$ (Bausch \& Lomb), segmented Weck-Cel ${ }^{\circledR}$ sponge (Beaver Visitec International, Waltham, MA, USA), or even plastic drape, avoids phototoxicity in addition to preventing corneal epithelial desiccation. Topical brimonidine tartrate (Alphagan ${ }^{\circledR} \mathrm{P}$; Allergan, Inc., Irvine, CA, USA) also provides excellent vasoconstriction.

During the procedure itself, it is important to use atraumatic technique throughout, respecting the conjunctival tissues. Specially designed conjunctival forceps (Bausch \& Lomb), with a Maumanee handle and Pierse tips, are ideally suited for manipulation of the delicate conjunctiva, thereby reducing the risk of conjunctival tears or button holes (see the section "Discussion of conjunctival forceps design" and Figure S1).

\section{Postoperative care}

At the conclusion of the case, a therapeutic bandage soft contact lens (THBL) should be considered because it accelerates reepithelialization and mitigates discomfort. This protection also provides a quantum leap in pain control. The THBL can be used with topical or local anesthesia, allowing the patient to see immediately postoperatively. The THBL can also be used with routine drops and ointment, and a double pressure patch, at the conclusion of retrobulbar or peribulbar block surgery. The patch is used only for the first night, while the THBL remains in place for at least 10-14 days. Some patients experience lens deposits and discomfort fairly early on into the postoperative healing period. The THBL should then be removed but replaced if there are any remaining epithelial defects whatsoever. Limbal sutures, if used, may eventually allow knot tips to protrude anteriorly, a problem for which the THBL is ideally suited. However, many patients tolerate the THBL up to the routine 3-week postoperative visit, at which time the THBL can be removed and the epithelium reassessed. Many patients no longer require a THBL at this 3 -week juncture, while many others benefit from an additional 3-4 weeks of THBL therapy.

Topical NSAID drops should be used with some precautions. Older, neurotrophic, dry eye, and very pale hypopigmented patients may experience delayed healing with topical NSAIDs, as may patients with extensive surgery, prolific application of cautery, preexisting scleral or peripheral corneal ectasia, exposed bare sclera, and toxic industrial or outdoor environmental challenges. NSAIDs 
should be recommended with reservations for all of these patient cohorts, whose pain can alternatively be controlled with topical mydriatics, such as homatropine 5\%, Mydriacyl ${ }^{\circledR}$ 1\% (Alcon Laboratories, Inc., Fort Worth, TX, USA), or Cyclogel 1\% (Alcon Laboratories, Inc.); however, Cyclogel, is particularly likely to cause stinging. Oral NSAIDs also provide excellent analgesia postoperatively, as does the THBL. Younger patients without other ocular conditions may benefit from postoperative NSAID drops, preferably bromfenac (Prolensa ${ }^{\mathrm{TM}}$; Bausch \& Lomb), nepafenac (Nevanac ${ }^{\circledR}$ and Ilevro $^{\circledR}$; Alcon Laboratories, Inc.), or generic diclofenac. Topical NSAIDs should absolutely be discontinued and completely avoided if the patient has bare sclera or threatened Dellen formation. LE ointment can provide overnight relief, in a preservative-free preparation, and can be applied even in the presence of a THBL. The ointment formulation provides particular postoperative benefit as it creates a physical "cushion" of sorts, to facilitate epithelial healing.

Strict attention should be paid to concomitant dry eye, in which case ipsilateral punctal occlusion, with a temporary collagen, long-lasting silicone, or even using electrocautery, should be strongly considered. Additional environmental, nutritional, and topical preservative-free tear replacement therapeutic measures to support dry eye therapy are also extremely important. LE suspension, gel, and ointment, are preferred choices for superficial punctate keratitis and dry eye. ${ }^{49}$

Because pterygia are both actinic and inflammatory in nature, progressive or recurrent degeneration can be avoided with aggressive UV protection and anti-inflammatory therapy. First, a subconjunctival triamcinolone acetonide (Kenalog ${ }^{\circledR}$; Bristol-Myers Squibb, New York, NY, USA) injection can be given immediately postoperatively in the operating room. Second, the patient must be warned to never expose the eyes to sunlight without wraparound UV sunglasses protection. Baseball-style caps, golf shades, or bonnet-style hats are also very useful. Third, aggressive postoperative application of topical steroids constitutes the mainstay of antirecurrence inflammation control and helps avoid scarring and neovascularization. Topical steroids should continue until all the signs of hypervascularity have vanished. The initial therapy with topical LE suspension or gel up to QID and LE ointment at bedtime is prescribed until the eye is completely "quiet", all hemorrhage has resolved, full comfort is restored, and all vasculature has returned to normal caliber. This may require up to 3 months in routine cases or much longer in complicated or high-recurrencerisk cases. Once the desired level of anti-inflammatory control has been achieved, the daytime LE treatment can be discontinued and the preservative-free ointment sustained at night (for up to 1 year postoperatively). This ensures compliance and avoids the appearance of limbal vascular tufts that lead to recurrence. For patients who experience difficulty with ointments, the mucoadhesive gel formulation provides sustained exposure to LE throughout the night as well as during waking hours. ${ }^{50}$

\section{Management of complications and recurrences}

Recurrence is heralded by hypervascularity, leading to limbal violation by abnormal conjunctival neovascularization (Figure 2). In the event of a recurrence, several courses of action can be taken to avoid repeat surgery, particularly if the recurrence is detected in its earliest stages (Table 3 ).

\section{Topical steroid therapy}

Topical steroid therapy prior to and following pterygium surgery is generally a long-term proposition. Patients treated with topical steroids prior to ocular surface surgery invariably fare better, with less immediate postoperative inflammation, fewer complications, a lower risk of recurrence and less extended requirements for inflammation control. Given the chronic nature of topical steroid needs in pterygium management, the potency and safety profile of LE make it an appropriate choice. For routine pterygium patients, LE suspension or gel BID, or LE ointment HS for a month prior to surgery provides sufficient control. Postoperatively, these patients fare well with QID drops or BID ointment for 2 weeks, then half that dose until there are no signs of recurrence and all redness has abated. More complicated cases, involving repeat surgeries and/or high-risk groups, will require more aggressive dosage and duration.

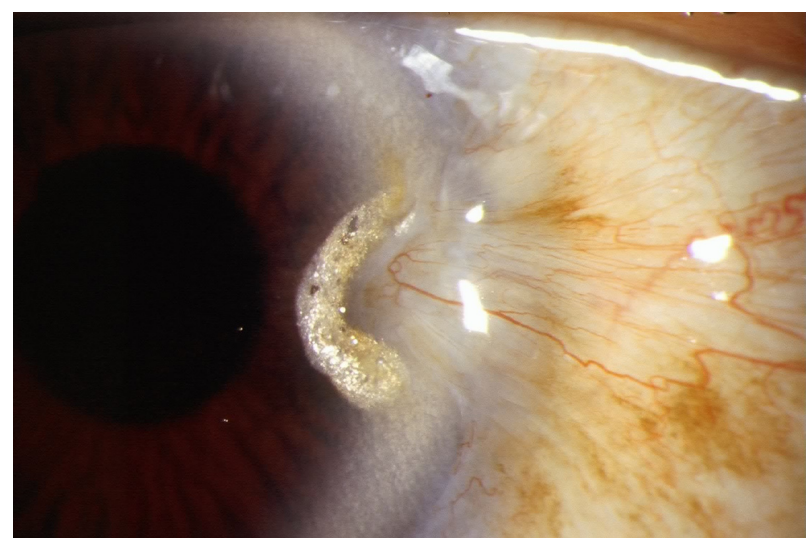

Figure 2 Untreated pterygium recurrence 3 years following successful surgery. Notes: Traction on the nasal conjunctiva and lipid exudate adjacent to the redundant corneal vascular anomalies are markers for chronicity. 
Table 3 Strategies for pterygium recurrence

I. Topical steroid therapy enhanced by increased frequency or potency

2. Oral doxycycline, especially in patients with ocular rosacea

3. Topical azithromycin, particularly for patients intolerant of oral doxycycline

4. Subconjunctival injection of antifibrotic agents: dexamethasone or triamcinolone +5 -fluorouracil + lidocaine

5. Subconjunctival injection of an anti-VEGF agent: bevacizumab (Avastin ${ }^{\circledR}$; Genentech Inc., South San Francisco, CA, USA)

6. Locally applied argon laser photocoagulation, enhanced by topical photosensitizer, such as sodium fluorescein

Abbreviation: VEGF, vascular endothelial growth factor.

\section{Oral doxycycline}

Continuous oral doxycycline can be a useful adjunct due to its beneficial nonantimicrobial effects, including anti-inflammatory, anticollagenase, meibomian lipid viscosity reduction, vascular stabilization, and anti-MMP 9 activities. Doxycycline is preferred over tetracycline or minocycline because of its superior efficacy, more versatile dosing, and a somewhat more favorable side effect profile. Nevertheless, many surgeons and dermatologists prefer minocycline. Fortunately, the nonantimicrobial beneficial effects of doxycycline do not require high dosages. Patients can begin on $100 \mathrm{mg}$ PO BID, eliminating the dinner dose after 10 days and then weaning to $50 \mathrm{mg}$ PO once daily (QD) for a month or so, and then to a sustained maintenance dose of $20 \mathrm{mg}$ PO QD if clinically indicated. Some more severely afflicted or high-body weight patients will require larger maintenance dosages. Patients who require continuous use may benefit from an annual break during the month of June when the sun is strongest in the Northern Hemisphere. The administration instructions for doxycycline and other tetracycline class antibiotics include the directive to "take on an empty stomach". In most patients, adherence to this recommendation can become difficult if they experience nausea as a result. Concomitant ingestion with dairy products and antacids should be avoided to optimize absorption.

\section{Topical azithromycin}

Topical azithromycin (AzaSite ${ }^{\circledR}$; Akorn, Inc., Lake Forest, IL, USA) has proven useful, not only for conjunctivitis but also for the same menu of nonantimicrobial benefits offered by oral doxycycline. Prolonged therapy can be useful but is often impractical due to cost. Topical azithromycin is particularly useful for patients who are intolerant of oral doxycycline. Many chronic patients benefit from 1 week per month of topical azithromycin HS, year round.

\section{Intraoperative subconjunctival steroid injections}

Intraoperative subconjunctival steroid injections provide excellent postoperative inflammation control in addition to topical therapy, allowing a significant reduction in the intensity of the postoperative steroid regimen. Topical $0.04 \%$ mitomycin $\mathrm{C}$ for intraoperative use is also available from both compounding pharmacies and as a stand-alone US Food and Drug Administration (FDA)-approved medication (Mitosol ${ }^{\circledR}$; Mobius Therapeutics LLC, St Louis, MO, USA). The potent antifibrotic effects of mitomycin $\mathrm{C}$ are essential to reduce the risk of recurrence in virtually all pterygium surgery patients. The dose must be titrated according to age, pigmentation, UV exposure, ocular surface inflammation, neovascularization, concomitant ocular surface disease, pterygium recurrence, previous conjunctival surgery or scarring, keloid formation, dermatologic disease, occupational or avocational environmental irritants, medication compliance, and the best judgment of the operating surgeon. Some surgeons also employ topical 5-FU for the same purpose, although its antifibrotic effect is not as potent as that of mitomycin C. On the other hand, 5-FU can readily be injected subconjunctivally, for postoperative patients with early or threatened recurrence as well as pyogenic granuloma formation or keloids, following surgery.

\section{Postoperative subconjunctival steroid and antifibrosis agent injections}

Postoperative subconjunctival steroid and antifibrosis agent injections are also beneficial in some cases of recurrent postoperative pterygium or corneal neovascularization. An excellent postoperative "cocktail" regimen for problematic patients includes $0.1 \mathrm{cc}$ of 5-FU and $0.3 \mathrm{cc}$ of dexamethasone, with $0.1 \mathrm{cc}$ of lidocaine placed into the syringe last so the anesthetic reaches the eye first on the way into the subconjunctival space. This $0.5 \mathrm{cc}$ injection can be given with a bevel-down, 30 gauge needle, tangential to the globe, and adjacent and posterior to the lurking recurrence site. The preparation includes the application of topical tetracaine gel and then, a couple of sterile cotton tip applicators that have been soaked in $4 \%$ lidocaine, placed serially into the inferior fornix and resting upon the injection site for several minutes prior to the 5-FU cocktail administration.

\section{Bevacizumab}

Bevacizumab (Avastin ${ }^{\circledR}$; Genentech Inc., South San Francisco, CA, USA) subconjunctival injections provide another strategy to manage neovascularization in both the 
cornea and the conjunctiva. The surgeon utilizes readily available syringes prepared by a network of reputable compounding pharmacies. This cost-effective anti-VEGF solution minimizes expense to the patient and allows for other subsequent treatments that might otherwise instigate the formation of yet more new unwanted vessels. Subconjunctival bevacizumab can be used alone or in conjunction with argon laser phototherapy, to obliterate specific conjunctival feeder vessels or intrastromal corneal vessels (Figure 3). The argon laser is typically set to repeat mode (as with a panretinal photocoagulation), 0.1 second duration, 100 micron spot size, and anywhere between 200 and $900 \mathrm{~mW}$. The procedure is comfortable with topical anesthesia, and retinal safety can be enhanced with preoperative pilocarpine miosis. Interestingly, topical sodium fluorescein, routinely used on the ocular surface for clinical diagnostic purposes, is also activated at the 514 nanometer Argon green wavelength incorporated into generations of therapeutic ophthalmic lasers; thus, the simple application of topical fluorescein acts as a photoactivator, significantly enhancing the local effects of the laser, particularly in foci where inflammation may potentiate fluorescein absorption through damaged ocular surface cells and compromised vascular endothelial junctions.

\section{Topical bevacizumab}

Topical bevacizumab drops have also been advocated ${ }^{51}$ in the control of corneal and conjunctival neovascularization. A simple $1 \%$ solution can readily be prepared by a qualified compounding pharmacy and applied BID to QID over a period of several weeks to several months. This often enables a significant therapeutic antineovascular effect in the cornea and conjunctiva - superficial vessels remain more susceptible

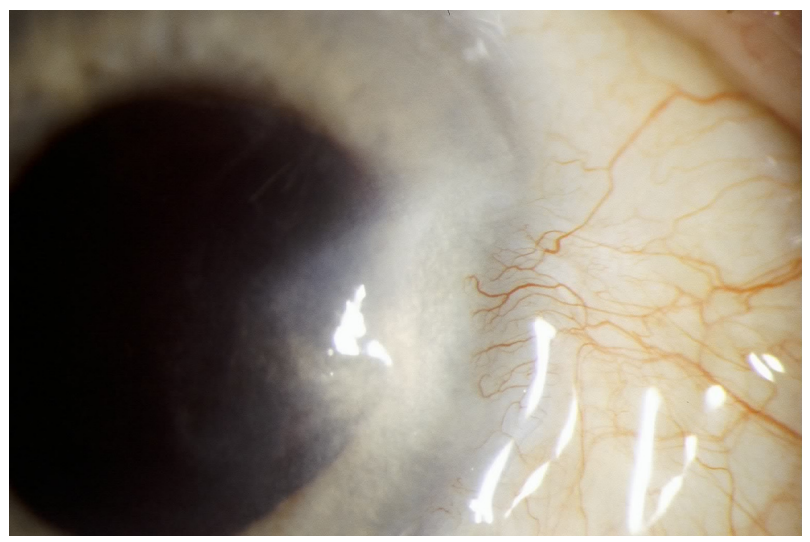

Figure 3 Early pterygium recurrence 2 months after successful surgery. Notes: The early vascular tufts can be treated with injections (steroid, 5-fluorouracil, or bevacizumab) or with focal argon laser therapy, as well as with increased topical steroid therapy. to all therapeutic efforts, while deeper interstitial vessels prove more recalcitrant.

\section{Preferred surgical technique for mild pterygia}

All pterygia, regardless of size or location (nasal, temporal, superior, or inferior) should be treated if an appropriate surgical technique, with the lowest recurrence rate and the maximum cosmetic effect, is available.

Smaller lesions without lid, caruncular, muscle, forniceal, or diffuse involvement can be remedied with a modified conjunctival rotational allograft technique (Figure 4). Once the conjunctival lesion has been delineated with Wescott scissors, the pterygium is grasped and carried forward to reveal the limbal region, which must be excised with a 64 Beaver blade (Beaver Visitec International). This dissection is continued anteriorly until all abnormal corneal tissue is removed, hopefully en bloc. After excision, aggressive cleaning of the corneal bed, with the 64 blade, ensures optimal cosmesis and recurrence avoidance. The cleanup can be augmented by gentle superficial removal of scarred anterior corneal stroma and basement membrane, with 0.12 forceps or Maumanee forceps and a Vannas scissors.

Care should always be taken not to create a new deeper plane, which risks unwarranted ectasia and even the threat of iatrogenic perforation in some challenging preexisting ectatic cases. Some surgeons advocate the use of a rotating burr or AlgerBrush (The Alger Company, Lago Vista, TX, USA) to clean the irregular nasal corneal stroma, with variable success, while other surgeons find burrs to be an unnecessary substitute for precise dissection and clean up. Once mitomycin C $0.04 \%$ has been applied for the appropriate

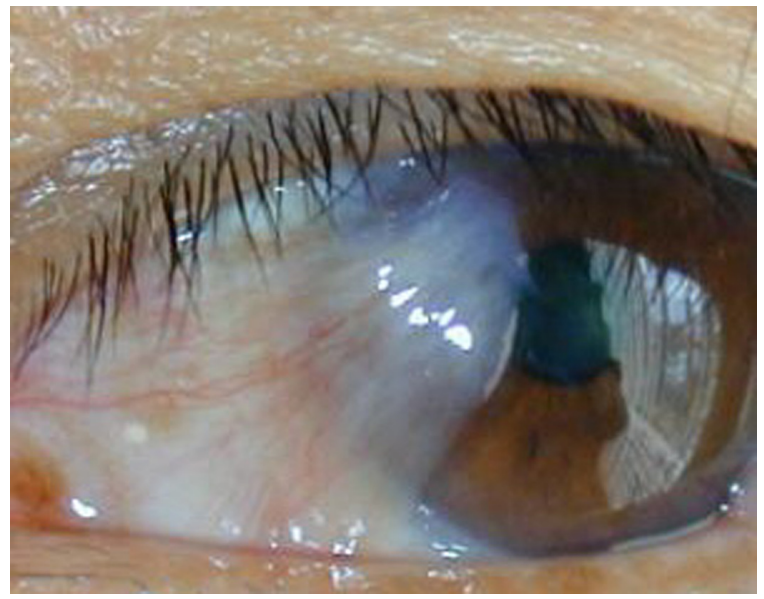

Figure 4 Typical fibrovascular nasal pterygium amenable to a superior and inferior rotational conjunctival graft procedure. 
amount of time, it can be vigorously irrigated away with six separate consecutive washings. It is imperative to remove all residual mitomycin $\mathrm{C}$. After each balanced salt solution (BSS) irrigation, residual saline can be quickly removed using a standard sterile $4 \times 4$ sponge applied directly to the surgical field.

Mitomycin $\mathrm{C}$ can be applied with small pieces of presoaked Weck-Cel sponge cut by the surgical technician. The best location is under the free edges of normal conjunctiva as well as directly upon the scarred corneal stroma and limbus. After excision and aggressive mitomycin $\mathrm{C}$ irrigation, there should be no stem cells or fibroblasts on the now bared limbus, so the rotational conjunctival tissue should be spared direct mitomycin $\mathrm{C}$ exposure. The astute surgeon should also consider pharmaceutical-grade Mitosol, which provides precut pledgets, precise concentration, and the convenience of a 2-year shelf life.

The rotational allograft is created by gently undermining the superior and the inferior limbus and bulbar conjunctiva immediately adjacent to the conjunctival excision site, then performing a snug peritomy limbal incision at the one- or two o'clock position. Rotation of the anterior limbal portion of each flap preserves limbal stem cell polarity while providing adequate closure tissue. Next, a double mattress suture is fashioned, starting with the scleral side of the superior flap, reentering approximately $5 \mathrm{~mm}$ away, then recreating the same mattress pattern inferiorly, with the last stroke passing the needle towards the sclera such that the knot will be buried. Prior to tying the double mattress suture, it must also be adequately anchored into the limbus, usually exactly at the three o'clock position in the right eye and the nine o'clock position in the left eye. This anchor suture must be deep enough into the limbus to avoid cheese-wiring, thereby relinquishing the limbal positioning and causing undesirable posterior migration of the conjunctival closure. The triple throw tie is carefully shimmied together, without placing excessive tension on the nylon suture until the wound is fully approximated. For larger dissections, excess tension with this suture can be relieved by loosening the lid speculum. Then the suture is cinched and the knot tied. The knot is closely trimmed and of course, covered by conjunctiva as well as the THBL at the conclusion of the case. Additional double mattress sutures are usually necessary posteriorly in order to fully close the wound, but anchor passes are not necessary and may be undesirable, particularly over the medial rectus muscle insertion.

Larger defects preclude this rotational technique. As it is imperative to leave no bare sclera, a covering must be provided, either from the superior ipsilateral host conjunctiva or from amniotic membrane. The former adds significant time to the case, while the latter adds significant expense. There is also a risk of pyogenic granuloma formation at the free autograft site, which should itself be closed with nylon suture. Tissue glue, either Tisseel or Evicel, provides excellent cosmesis and speedy surgery. Glue, unfortunately, adds another significant expense to the case, which may render this marvelous technology fiscally unacceptable for a nonhospital-based surgery center. Despite their inherent efficiencies, freestanding, physician-owned ambulatory surgery centers (ASCs) receive $60 \%$ of the facility fee given to hospital-based or -owned facilities. Furthermore, nonhospital ASCs are not allowed pass-through spending allowances for indicated supplies, such as amniotic membrane, tissue glue, some glaucoma shunts, donor cornea, donor sclera, pericardium, and many other implanted materials, including postevisceration and enucleation implants. Thus, these supplies can overconsume the facility fee and subject these procedures to a substantial fiscal loss. 10-0 nylon sutures are far more economical, albeit far less "high tech" than amnion or fibrin glue products.

Generally, the knots are very well tolerated and do not require removal in the clinic, even the nylon will resorb and dissolve over the course of 6-12 months. However, many patients manage to extrude the sutures while fully denying any rubbing behavior or excess physical activity. At bedtime, the use of a hard, clear eye shield, secured with paper tape, is routinely recommended for the first 3 weeks postoperatively, longer for patients who are agitated or have insomnia. When the sutures loosen, they can readily be removed at the slit lamp, with a 15 degree blue blade and jewelers forceps. Topical bromfenac and tetracaine (Tetravisc; Ocusoft, Rosenberg, TX, USA) provide more than sufficient analgesia for the vast majority of patients.

\section{Case presentation}

The operative approach to a typical case, as managed by one of the authors (AM) is presented (Figure 5).

For the procedure, intravenous sedation was used. The eye was prepped and draped in the usual sterile fashion, and a lid speculum was inserted. Brimonidine tartrate (Alphagan P) drops were then applied topically to constrict the blood vessels for the subsequent control of hemostasis, and $2 \%$ lidocaine gel was applied for topical anesthesia. The pterygium and the semilunar fold were identified. Using a 0.12 forceps to pick up the semilunar fold, a peritomy was made in front of the semilunar fold and carried superiorly and inferiorly toward the fornix. Then, all of the underlying fibrovascular 
A

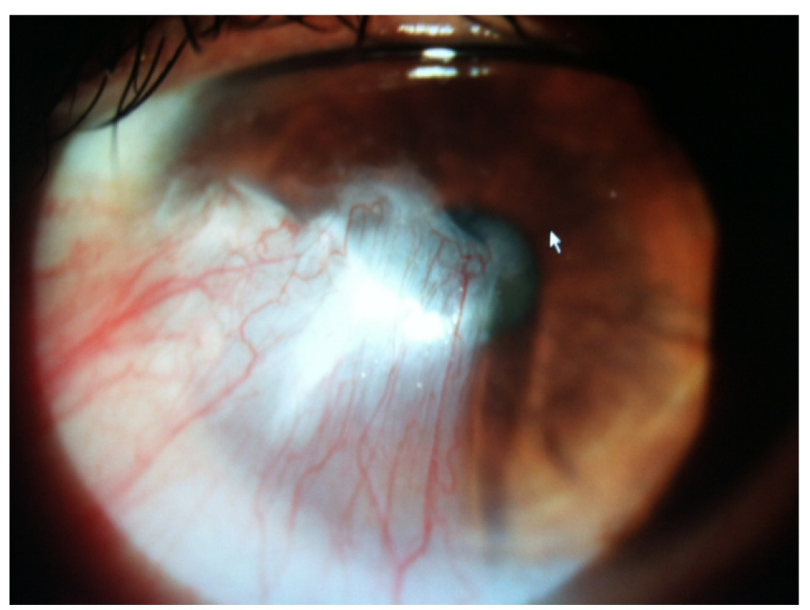

B

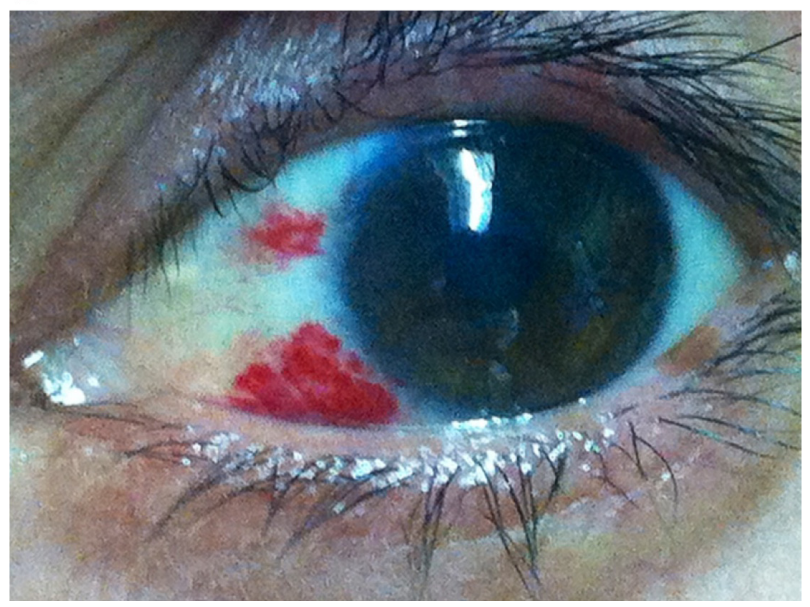

Figure 5 Pterygium case (A) preoperatively and (B) 2-weeks postoperatively.

tissue was picked up, by the 0.12 forceps, as high as possible (to remove most from the medial and inferior fornix) until all visible medial rectus was free from the dense fibrovascular tissue. This was accomplished using the Mansur-Aran Graft Harvesting Pterygium Debunking Scissors (Rhein Medical Inc., St Petersburg, FL, USA) while the scissors were used to truncate it from the base (allowing the remaining tissue to retract into the deep fornix after truncation) (Figure 6). This

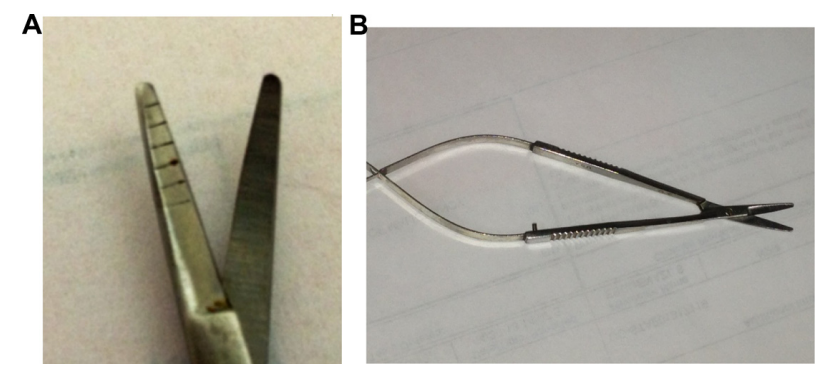

Figure 6 Mansur-Aran Graft Harvesting Pterygium Debunking Scissors (Rhein Medical Inc., St Petersburg, FL, USA): (A) tip and (B) full view. dissection left the muscle sheath, as well as the underlying Tenon's capsule, intact - when the underlying Tenon's capsule looks glistening, mobile, and thin, it is left intact. The above dissection was carried out superiorly and inferiorly toward the fornix. Hence, the entire pterygium head and body, including the underlying fibrovascular tissue, were dragged by the forceps all the way toward the nasal limbus, where the head was detached with blunt dissection. The remnant tissue over the cornea was cleared by grasping with a 0.12 forceps and \#64 blade scraping or dental burr polishing. Sponges soaked in $0.04 \%$ mitomycin $\mathrm{C}$ were inserted under the surrounding conjunctiva, in the fornix space between the Tenon's capsule and the conjunctiva from the limbus. A total of two or three sponges was used and incubated for 30 seconds. The edge of the mitomycin $\mathrm{C}$ sponge was bent to contact the cut conjunctival edges. After incubation, the sponges were removed, and the area was irrigated with a copious amount of BBS. Using two 0.12 forceps, one grasping the conjunctival edge and the other the edge of Tenon's capsule, the gaps between the two were identified and sealed by applying one drop each of the two components of the fibrin glue. Thereafter, a free graft of superior conjunctiva containing limbal stem cells was placed on the recipient site and stretched with a surgical spatula. Next, using two 0.12 forceps, one grasping the conjunctival edge and the other the edge of Tenon's capsule, the gaps in between the two were identified and sealed by sequentially applying one drop each of the two components of the fibrin glue.

The harvesting site was then covered with conjunctiva glue in a sequential manner. The excess autograft tissue was trimmed, as was as the fibrin glue. Then, $0.220 \mathrm{cc}$ of triamcinolone acetonide $40 \mathrm{mg} / \mathrm{cc}$ (Kenalog) was injected into the caruncle region, and topical tobramycin-dexamethasone (Tobradex, Alcon Laboratories, Inc.) ointment was applied. The eye was patched and shielded.

After surgery, topical besifloxacin was administered, one drop TID for 7 days, and then an LE suspension, one drop TID for 5 weeks, then finished, or titrated downward over a longer period of time according to the individual patient's inflammatory response. Figure 5 documents the pterygium preoperatively and 2-weeks postoperatively.

In our center, the patient is generally seen 1 day later to look for conjunctival gaps only when the technique was aggressive. We have found that only about $1 \%$ of cases have a gap, which if greater than $2 \mathrm{~mm}$ can be re-glued in any chosen manner. The next follow-up visit is usually scheduled at 1 week, and the final follow-up visit is at 4-6 weeks; generally, $98 \%$ of all signs and symptoms of regrowth occur 
within this period of time. With regrowth, about $1 \%$ of cases show aggressive vessels, usually from the inferior cul de sac; these patients are treated with $0.1 \mathrm{cc}$ of bevacizumab and $0.2 \mathrm{cc}$ of triamcinolone acetonide, injected under the sites of aggressive vessels, with attention to the graft itself. Further follow up is then scheduled 2 weeks later, by which time about $99 \%$ of cases resolve; the remainder must undergo another surgical procedure.

Overall, this case illustrates the fact that pterygium surgery is very complex and requires vast surgical experience to accomplish the best end result - no recurrence and excellent cosmesis. Debunking of all the fibrovascular tissue, thorough cleaning of the medial rectus, and a limboconjunctival autograft with no Tenon's capsule that covers all of the excised tissue area are vital. Tisseel allows secure placement of the graft, and the application of mitomycin $\mathrm{C}$ for 30 seconds in the cul de sac is also extremely important. The impregnation of the graft with triamcinolone acetonide prevents edema. The use of LE suspension, gel, or ointment for 5 weeks gives this surgical approach the final step to accomplish a successful result.

\section{Conclusion}

Despite two millennia of experience with this disease, the ultimate objective continues to be achieving a more thorough understanding of its pathogenesis, with the aim of developing interventions to reduce both pterygium incidence and postsurgical recurrence. Until that time, the immediate goal is to optimize surgical practices, to ensure the best possible outcomes. Based on the authors' experience, LE, including the preservative-free ointment formulation, is a safe and effective component of the perioperative regimen for this complex ocular condition. Prospective clinical studies are needed to further clarify the role of LE in the management of pterygium.

\section{Acknowledgments}

The authors wish to thank Anthony Shardt, MD, of Churchill Communications (Maplewood, NJ) for writing assistance. This assistance was funded by Bausch \& Lomb. The authors retained full control of the manuscript content.

\section{Disclosure}

JDS, AM, and JAH are consultants for Bausch \& Lomb. TLC is an employee of Bausch \& Lomb. JDS is also a consultant for Abbvie, Alcon, Allergan, Merck, NiCox, Omeros, and Science Based Health. The authors report no other conflicts of interest in this work.

\section{References}

1. Anderson DM, editor. Dorland's Illustrated Medical Dictionary. 31st ed. Philadelphia, PA: Saunders; 2007.

2. Johnson RD, Pai VC, Hoft RH. Historical approaches to pterygium surgery, including bare sclera and adjunctive beta radiation techniques. In: Hovanesian JA, editor. Pterygium: Techniques and Technologies for Surgical Success. Thorofare, NJ: Slack Incorporated; 2012:2012: $27-36$.

3. Chui JJY, Coroneo MT. Pterygium pathogenesis, actinic damage, and recurrence. In: Hovanesian JA, editor. Pterygium: Techniques and Technologies for Surgical Success. Thorofare, NJ: Slack Incorporated; 2012:1-26.

4. Johnston SC, Williams PB, Sheppard JD Jr. A Comprehensive System for Pterygium Classification [abstract]. Investig Ophthalmol Vis Sci. 2004;45:2940.

5. Chui J, Di Girolamo N, Wakefield D, Coroneo MT. The pathogenesis of pterygium: current concepts and their therapeutic implications. Ocul Surf. 2008;6(1):24-43.

6. Coroneo MT, Di Girolamo N, Wakefiled D. The pathogenesis of pterygia. Curr Opin Ophthalmol. 1999;10(4):282-288.

7. Di Girolamo N, Chui J, Coroneo MT, Wakefield D. Pathogenesis of pterygia: role of cytokines, growth factors, and matrix metalloproteinases. Prog Retin Eye Res. 2004;23(2):195-228.

8. van Setten G, Aspiotis M, Blalock TD, Grotendorst G, Schultz G. Connective tissue growth factor in pterygium: simultaneous presence with vascular endothelial growth factor-possible contributing factor to conjunctival scarring. Graefes Arch Clin Exp Ophthalmol. 2003;241(2): 135-139.

9. Kheirkhah A, Casas V, Sheha H, Raju VK, Tseng SC. Role of conjunctival inflammation in surgical outcome after amniotic membrane transplantation with or without fibrin glue for pterygium. Cornea. 2008;27(1):56-63.

10. Kheirkhah A, Nazari R, Nikdel M, Ghassemi H, Hashemi H, Behrouz MJ. Postoperative conjunctival inflammation after pterygium surgery with amniotic membrane transplantation versus conjunctival autograft. $\mathrm{Am}$ J Ophthalmol. 2011;152(5):733-738.

11. Comstock TL, Decory HH. Advances in corticosteroid therapy for ocular inflammation: loteprednol etabonate. Int J Inflam. 2012;2012: 789623.

12. Alberth M, Wu WM, Winwood D, Bodor N. Lipophilicity, solubility and permeability of loteprednol etabonate: a novel, soft anti-inflammatory steroid. J Biopharm Sci. 1991;2(2):115-125.

13. Bodor N, Buchwald P. Soft drug design: general principles and recent applications. Med Res Rev. 2000;20(1):58-101.

14. Samudre SS, Lattanzio FA, Williams PB, Sheppard JD. Comparison of topical steroids for acute anterior uveitis. J Ocul Pharmacol Ther. 2004;20(6):533-547.

15. Bodor N, Loftsson T, Wu WM. Metabolism, distribution, and transdermal permeation of a soft corticosteroid, loteprednol etabonate. Pharm Res. 1992;9(10):1275-1278.

16. Wu WM, Huang F, Lee Y, Buchwald P, Bodor N. Pharmacokinetics of the sequential metabolites of loteprednol etabonate in rats. $J$ Pharm Pharmacol. 2008;60(3):291-297.

17. Amon M, Busin M. Loteprednol etabonate ophthalmic suspension $0.5 \%$ : efficacy and safety for postoperative anti-inflammatory use. Int Ophthalmol. 2012;32(5):507-517.

18. Bartlett JD, Horwitz B, Laibovitz R, Howes JF. Intraocular pressure response to loteprednol etabonate in known steroid responders. J Ocul Pharmacol. 1993;9(2):157-165.

19. Holland EJ, Bartlett JD, Paterno MR, Usner DW, Comstock TL. Effects of loteprednol/tobramycin versus dexamethasone/tobramycin on intraocular pressure in healthy volunteers. Cornea. 2008;27(1): $50-55$.

20. Holland EJ, Djalilian AR, Sanderson JP. Attenuation of ocular hypertension with the use of topical loteprednol etabonate $0.5 \%$ in steroid responders after corneal transplantation. Cornea. 2009;28(10): 1139-1143. 
21. Novack GD, Howes J, Crockett RS, Sherwood MB. Change in intraocular pressure during long-term use of loteprednol etabonate. J Glaucoma. 1998;7(4):266-269.

22. Stewart R, Horwitz B, Howes J, Novack GD, Hart K. Double-masked, placebo-controlled evaluation of loteprednol etabonate $0.5 \%$ for postoperative inflammation. Loteprednol Etabonate Post-operative Inflammation Study Group 1. J Cataract Refract Surg. 1998;24(11): 1480-1489.

23. The Loteprednol Etabonate Postoperative Inflammation Study Group 2. A double-masked, placebo-controlled evaluation of $0.5 \%$ loteprednol etabonate in the treatment of postoperative inflammation. Ophthalmology. 1998;105(9):1780-1786.

24. Comstock TL, Paterno MR, Singh A, Erb T, Davis E. Safety and efficacy of loteprednol etabonate ophthalmic ointment $0.5 \%$ for the treatment of inflammation and pain following cataract surgery. Clin Ophthalmol. 2011;5:177-186

25. Fong R, Leitritz M, Siou-Mermet R, Erb T. Loteprednol etabonate gel $0.5 \%$ for postoperative pain and inflammation after cataract surgery: results of a multicenter trial. Clin Ophthalmol. 2012;6:1113-1124.

26. Rajpal RK, Roel L, Siou-Mermet R, Erb T. Efficacy and safety of loteprednol etabonate $0.5 \%$ gel in the treatment of ocular inflammation and pain after cataract surgery. J Cataract Refract Surg. 2013;39(2): $158-167$.

27. Nguyen HT, Samudre SS, Lattanzio FA Jr, Williams PB, Sheppard JD Jr. Loteprednol etabonate (Lotemax, $0.5 \%$ ) reduces inflammatory response associated with pterygium progression. Poster presented at: the 2008 Meeting of the Association for Research in Vision and Ophthalmology (ARVO); April 27-May 1, 2008; Fort Lauderdale, Florida.

28. Nguyen HT, Samudre SS, Lattanzio FA, Williams PB, Sheppard JD Loteprednol etablonate reduces Inflammatory Response associated with Pterygium Progression. Investig Ophthalmol Vis Sci. 2008; 49: 6027.

29. Ang LP, Chua JL, Tan DT. Current concepts and techniques in pterygium treatment. Curr Opin Ophthalmol. 2007;18(4):308-313.

30. Kaufman SC, Jacobs DS, Lee WB, Deng SX, Rosenblatt MI, Shtein RM. Options and adjuvants in surgery for pterygium: a report by the American Academy of Ophthalmology. Ophthalmology. 2013;120(1):201-208

31. Zheng K, Cai J, Jhanji V, Chen H. Comparison of pterygium recurrence rates after limbal conjunctival autograft transplantation and other techniques: meta-analysis. Cornea. 2012;31(12):1422-1427.

32. Cho H, Chuck RS. Pterygium excision and placement of amniotic membrane grafts. In: Hovanesian JA, editor. Pterygium: Techniques and Technologies for Surgical Success. Thorofare, NJ: Slack Incorporated; 2012:91-100.

33. Tananuvat N, Martin T. The results of amniotic membrane transplantation for primary pterygium compared with conjunctival autograft. Cornea. 2004;23(5):458-463.

34. Luanratanakorn P, Ratanapakorn T, Suwan-Apichon O, Chuck RS. Randomised controlled study of conjunctival autograft versus amniotic membrane graft in pterygium excision. Br J Ophthalmol. 2006;90(12): 1476-1480.

35. Hovanesian JA, Behesnilian AS. Pterygium excision with a conjunctival autograft and prophylactic placement of subconjunctival amniotic membrane surrounding the excision site. In: Hovanesian JA, editor. Pterygium: Techniques and Technologies for Surgical Success. Thorofare, NJ: Slack Incorporated; 2012:101-110.
36. Hardten DR. Fibrin tissue adhesive. In: Hovanesian JA, editor. Pterygium: Techniques and Technologies for Surgical Success. Thorofare, NJ: Slack Incorporated; 2012:49-54.

37. Singh PK, Singh S, Vyas C, Singh M. Conjunctival autografting without fibrin glue or sutures for pterygium surgery. Cornea. 2013;32(1): 104-107.

38. Almond MC, Dastrup BT, Kaufman SC. 5-fluorouracil and mitomycin-C: adjuncts to pterygium surgery. In: Hovanesian JA, editor. Pterygium: Techniques and Technologies for Surgical Success. Thorofare, NJ: Slack Incorporated; 2012:55-64.

39. Raiskup F, Solomon A, Landau D, Ilsar M, Frucht-Pery J. Mitomycin C for pterygium: long term evaluation. Br J Ophthalmol. 2004;88(11): 1425-1428.

40. Mastropasqua L, Carpineto P, Ciancaglini M, Enrico Gallenga P. Long term results of intraoperative mitomycin $\mathrm{C}$ in the treatment of recurrent pterygium. Br J Ophthalmol. 1996;80(4):288-291.

41. Rubinfeld RS, Pfister RR, Stein RM, et al. Serious complications of topical mitomycin-C after pterygium surgery. Ophthalmology. 1992;99(11):1647-1654.

42. Kheirkhah A, Hashemi H, Adelpour M, Nikdel M, Rajabi MB, Behrouz MJ. Randomized trial of pterygium surgery with mitomycin C application using conjunctival autograft versus conjunctival-limbal autograft. Ophthalmology. 2012;119(2):227-232.

43. Sharma A, Gupta A, Ram J, Gupta A. Low-dose intraoperative mitomycin- $\mathrm{C}$ versus conjunctival autograft in primary pterygium surgery: long term follow-up. Ophthalmic Surg Lasers. 2000;31(4): 301-307.

44. Yamamoto T, Varani J, Soong HK, Lichter PR. Effects of 5-fluorouracil and mitomycin $\mathrm{C}$ on cultured rabbit subconjunctival fibroblasts. Ophthalmology. 1990;97(9):1204-1210.

45. Bekibele CO, Ashaye A, Olusanya B, et al. 5-Fluorouracil versus mitomycin $\mathrm{C}$ as adjuncts to conjunctival autograft in preventing pterygium recurrence. Int Ophthalmol. 2012;32(1):3-8.

46. Kumar DA, Agarwal A. Pterygium: postoperative management and complications. In: Hovanesian JA, editor. Pterygium: Techniques and Technologies for Surgical Success. Thorofare, NJ: Slack Incorporated; 2012:111-120.

47. Torres-Gimeno A, Martínez-Costa L, Ayala G. Preoperative factors influencing success in pterygium surgery. BMC Ophthalmol. 2012;12:38

48. Hirst LW. Recurrence and complications after 1,000 surgeries using pterygium extended removal followed by extended conjunctival transplant. Ophthalmology. 2012;119(11):2205-2210.

49. Sheppard JD, Scoper SV, Samudre S. Topical loteprednol pretreatment reduces cyclosporine stinging in chronic dry eye disease. J Ocul Pharmacol Ther. 2011;27(1):23-27.

50. Coffey MJ, Decory HH, Lane SS. Development of a non-settling gel formulation of $0.5 \%$ loteprednol etabonate for anti-inflammatory use as an ophthalmic drop. Clin Ophthalmol. 2013;7:299-312.

51. Kim SW, Ha BJ, Kim EK, Tchah H, Kim TI. The effect of topical bevacizumab on corneal neovascularization. Ophthalmology. Epub April 24, 2008. 


\section{Supplementary material Discussion of conjunctival forceps design}

The Sheppard conjunctival forceps (Bausch \& Lomb, Rochester, NY, USA) has been specifically designed for the intricate needs of pterygium surgery (Figure S1). The longhandle Maumenee design body enables comfortable anatomical hand and wrist positioning parallel to the surgical field, with minimal view obstruction, even while working deep in the nasal canthus. The leveraged grasp reduces surgeon fatigue compared with the classic 0.12 tissue forceps. The angular 45-degree tip configuration allows full visualization of the grasped conjunctival tissues. The rounded rather than toothed Pierse tips prevent damaging button holes or tears in the conjunctiva during tissue manipulation, particularly when the tissue must be stretched during a rotational autograft or lengthy dissection.

Minimization of the use of cautery to the bare scleral surface avoids scarring, inflammation, and unsightly charcoal burns, as well as potential rare but disfiguring scleral ectasia and necrosis. Hemostasis can often be achieved simply with topical 1:10,000 epinephrine solution.

For suturing, a 10-0 nylon suture should be used. It is familiar, the needle is atraumatic, and most importantly, there is no tissue reaction whatsoever. The sutures often remain intact, subconjunctival, unnoticed, and inert until full hydrolysis occurs 6-18 months postoperatively. A double mattress technique should be used, to avoid cheese-wiring

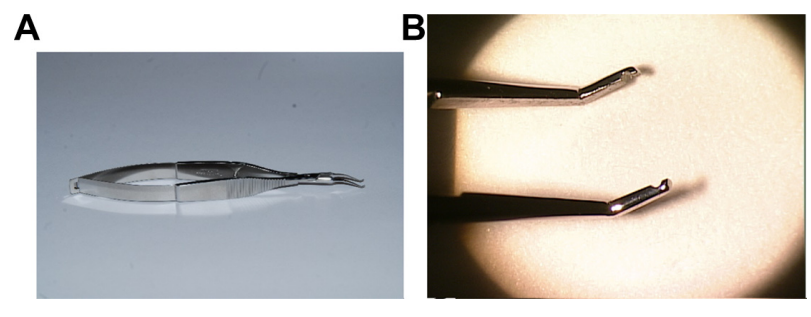

Figure SI Sheppard conjunctival forceps (Bausch \& Lomb, Rochester, NY, USA): (A) full view and (B) forceps tips.

through the opposing conjunctival edges. In order to bury the double mattress suture knot subconjunctivally, the first pass should be made from the posterior conjunctival surface, and the last pass should be towards the posterior conjunctival surface. The most anterior conjunctival suture should be anchored in the limbal episcleral tissue with a third bite, to avoid posterior migration.

Fibrin tissue glue and amniotic membrane are outstanding adjuncts to successful surgery. However, for smaller lesions, the potential benefits could be outweighed by the relative costs: hundreds of dollars each for the glue and the membrane, compared with about $\$ 30$ for the 10-0 nylon suture.

The duration of topical mitomycin C $0.04 \%$ treatment should be titrated to the patient's risk of recurrence. Astute clinical judgment, based upon clinical experience, is required to match application duration to the individual patient's needs: higher-risk patients should require longer exposure.
Clinical Ophthalmology

\section{Publish your work in this journal}

Clinical Ophthalmology is an international, peer-reviewed journal covering all subspecialties within ophthalmology. Key topics include: Optometry; Visual science; Pharmacology and drug therapy in eye diseases; Basic Sciences; Primary and Secondary eye care; Patient Safety and Quality of Care Improvements. This journal is indexed on

\section{Dovepress}

PubMed Central and CAS, and is the official journal of The Society of Clinical Ophthalmology (SCO). The manuscript management system is completely online and includes a very quick and fair peer-review system, which is all easy to use. Visit http://www.dovepress.com/ testimonials.php to read real quotes from published authors. 